\section{New student medical journal launched}

I t's certainly the norm in human reproduction that birth follows conception by nine months, but not in journology.

Yet a pair of University of British Columbia medical students defied the journalistic odds on Sept. 8 by launching Canada's newest student medical journal - UBC Medical Journal (www.med.ubc.ca/research/ubcmj.htm) - a scant three trimesters after they conceived of the notion.

The rapid start-up is testimony to the enthusiastic response and support of students and faculty, says coeditor Pamela Verma, who conceived the journal, along with fellow medical student Diane $\mathrm{Wu}$, in January, during their first year of medical school.

Verma's interest stemmed from a "passion for research" she developed while conducting studies in the social sciences and neuroscience during her pursuit of an undergraduate degree in cell and developmental biology. "I want to use my medical education to help clinically and in the medical research discourse," she says. "This is our opportunity to think critically."

It appears to be an opportunity that many others sought, judging from the "overwhelming" response Verma and Wu received while developing the initiative. An early workshop on writing and reviewing was standing room only; later 70 people applied to review articles.

UBC Dean of Medicine Dr. Gavin Stuart and many other professors and professionals also lent a hand, Verma says. The journal now has 26 staffers and 29 peer reviewers. Papers are

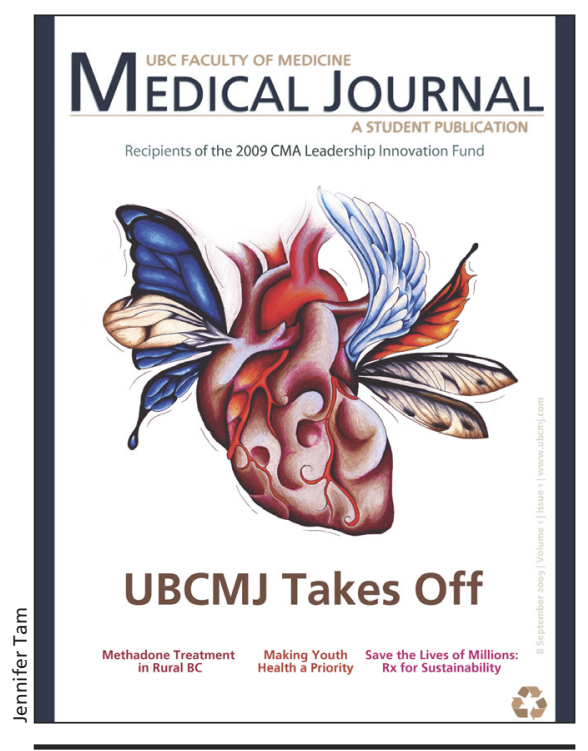

The cover illustration of UBCMJ inaugural issue is "Atrial Flutter" by medical student Alexandra Otto. It was an entry in the Heartfelt Images Photo Contest wherein first-year UBC medical and dental students are invited to submit photographs or other art forms that relate to concepts they learn in their cardiovascular curriculum.

reviewed by a faculty member and one or two students.

In their inaugural editorial, Verma and $\mathrm{Wu}$ emphasize the importance of engaging students on all three UBC campuses (Vancouver, Victoria and Prince George) that comprise one of North America's first distributed medical programs.

The 40-page first issue is distinctly British Columbian, with a research article on methadone treatment in Prince George, a made-in-BC treatment for adhesive capsulitis and community partnerships at the Vancouver Native Health Clinic.

"The first issue couldn't have been better," says Verma. "These are all vital issues for clinicians and clinicians in training."

Print copies of the premiere issue will be distributed to first- and secondyear medical students, primarily as a memento and an expression of appreciation to those who helped develop the project.

Ultimately, though, the coeditors say the journal's future lies within the electronic realm. Plans are to include interactive features that allow for networking and the exchange of ideas. "Online is the life of the journal," says Verma.

The journal is funded by advertising and a Canadian Medical Association Leadership Innovation Award, as well as monies from the British Columbia Medical Association, UBC Faculty of Medicine Council of Undergraduate Deans and UBC Medical Undergraduate Society.

Hoping to establish itself as one of Canada's, if not the world's, leading student-run medical publications, the journal joins the ranks of at least four other Canadian journals:

- University of Toronto Medical Journal: www.utmj.org/

- McGill Journal of Medicine: www .med.mcgill.ca/mjm/

- McMaster University Medical Journal: http://mumj.org/

- University of Alberta Health Sciences Journal: www.uahsj.ualberta.ca/ — Barbara Sibbald, CMAJ

DOI:10.1503/cmaj.109-3048 